\title{
УДК: 336.025
}

\section{Криминализация финансовых отношений как угроза возможностям финансового обеспечения стабильного экономического роста}

\author{
Д-р экон. наук, профессор Литвиненко А.H. Lanfk@ mail.ru \\ Санкт-Петербургский университет МВД России \\ 198206, Россия, Санкт-Петербург, ул. Летчика Пилютова, д. 1 \\ Д-р экон. наук, профессор Алпатов Г.Е.g.alpatov@ spbu.ru \\ Санкт-Петербургский государственный университет, \\ 199034, Россия, Санкт-Петербург, Университетская наб. д. 7-9
}

\begin{abstract}
В статье рассматриваются вопросы анализа криминализации финансовых отношений. Целью статьи является разработка научно-методического подхода для определения направлений противодействия криминализации финансовых отношений в условиях российской экономической модели. В качестве основной гипотезы постулируется предположение о том, что природа криминализации финансовых отночений обусловлена не столько изъянами экономической политики, сколько спецификой сформировавшейся институциональной среды. Характерными чертами этой среды являются борьба теневого права организованной преступности с официальным правом и потеря элитами национальной идентичности. Авторы приходят к выводу, что ключевые инструменты противодействия криминализации финансовых отношений, такие как запрет офиорных юрисдикций, должны иметь наднациональный характер.

Ключевые слова: криминализация финансовых отношений, угроза экономического роста, противодействие криминализации, финансовая безопасность, финансы офшоров.
\end{abstract}

DOI:10.17586/2310-1172-2016-9-3-30-35

\section{Criminalization of financial relations as a threat to financial provision of achievement of sustained economic growth}

\author{
D.Sc., professor Litvinenko A.N. Lanfk@mail.ru \\ St. Petersburg University of the Ministry of Interior of the Russian Federation \\ 198206, Russia, Saint-Petersburg, Letchika Pilutova st., 1 \\ D.Sc., professor Alpatov G.E.g.alpatov@spbu.ru \\ St. Petersburg State University \\ 199034, Russia, Saint-Petersburg, Tchaikovsky st., 62
}

The article deals with the analysis of the criminalization of financial relations. The aim of the article is to develop a scientific and methodical approach to determine the directions of counteraction of criminalization of financial relations in the Russian economic model. As the main hypothesis we postulated the assumption that the nature of the criminalization of financial relations is due not so much a flawed economic policy but the specifics of the formed institutional environment. Characteristic features of this environment are combating the shadow law of organized crime with the official law and the loss of national identity by the elites. The authors conclude that the key instruments to counter the criminalization of financial relations, such as the ban on offshore jurisdictions should have a supranational character.

Keywords: criminalization of financial relations, the threat to economic growth, opposition to criminalization, financial secrecy; offshore finance.

В новой Стратегии национальной безопасности Российской Федерации к числу главных стратегических угроз национальной безопасности в области экономики - наряду с другими двенадцатью угрозами - относится сохранение значительной доли теневой экономики, условий для коррупции и криминализации хозяйственнофинансовых отношений [1, ст. 56]. О масштабах криминализации финансовых отношений в экономике России свидетельствуют и официальные данные правоохранителей, и независимые экспертные оценки [10, с.88], [11], [12]. Объединяет эти оценки одно - стабильность и темпы экономического роста во многом страдают из-за наличия негативных явлений в финансово-кредитной сфере. Сегодня не разрешено противоречие между не 
снижающимся уровнем криминализации финансовых отношений в российской экономике и отсутствием эффективных инструментов противодействия этому явлению.

Поэтому остается актуальной задача - на основе анализа сложившейся ситуации выявить закономерности и тенденции криминализации в финансово-кредитной сфере и предложить направления и методы минимизации их влияния для принятия соответствующих управленческих решений.

Легализация и оборот инвестиционных капиталов криминального происхождения вступают в противоречие с российскими национальными интересами. Это угрожает криминализацией финансовоэкономических отношений и приводит к формированию серьезной угрозы экономической безопасности страны. Но многообразие форм и способов легализации делает решение задачи противодействия со стороны регулятора крайне затратным. Например, Российские эмитенты активно используют инструмент АДР, размещая свои акции в ущерб российским биржам в США ради привлечения зарубежного капитала. АДР выпускали МТС, Вымпелком, Ростелеком, Татнефть, Лукойл, Газпром, Мечел и многие другие. Кто покупает АДР? Является ли покупка депозитарных расписок, а следовательно и самих акций ведущих российских компаний, легализацией вывезенного за рубеж капитала или это законопослушные иностранные инвесторы инвестируют в наш бизнес? Разнообразие потоков капитала, рождает конкуренцию и вместе с ней улучшение инвестиционного климата, способствующего экономическому росту. Поэтому задача регулятора вначале заключается в отделении тех, кто легализует капитала криминального происхождения от остальных инвесторов. Однако сложность заключается в том, что методы противодействия криминальным действиям не удается сделать узко целенаправленными, и они неминуемо распространяют ограничения на широкий круг инвесторов, тормозя инвестиционный процесс. Например, запрет на вывоз капитала как возможный инструмент ограничивает вывоз не только доходов криминального происхождения, но и тормозит свободное движение товаров и капитала вообще. Ограничение на импорт, а импорт означает встречное движение денег за рубеж, снижает эффективность внутреннего производства, защищенного от внешней конкуренции. Эти меры характерные для раннего меркантилизма XVIXVII вв. находят многих сторонников в России. Усиление контроля со стороны государства озачает с позиции бизнеса усиление ограничений, распространяющихся на всех, а не только на противоправную деятельность части, что ведет к росту трансакционных издержек и повышению цен для широкого круга потребителей не только на товарных, но и на денежном рынке.

В рамках настоящей статьи будем понимать под понятием криминализации процесс, реализуемый не только противоправными средствами, но и с использованием иных легальных технологий, которые минимизируют государственный контроль за преступностью в финансовой сфере. Речь идет о следующих технологиях: уголовно-правовая декриминализация этих деяний; частичная десистематизация уголовного законодательства; законодательное ограничение компетенции деятельности правоохранительных органов, специализирующихся на выявлении и раскрытии преступлений, совершаемых преступными организациями; развал уголовных дел и др. [3].

Будем исходить из гипотезы, состоящей в том, что природа криминализации финансовых отношений обусловлена не только изъянами экономической политики. Процесс криминализации нельзя рассматривать вне его связи с институциональной средой, порождающей и подпитывающей существование криминальных сообществ.

Основной характеристикой этой среды является сегодняшняя неолиберальная модель российской экономики, сочетающаяся с личной унией капитала и власти, которая имеет слабую мотивацию для противодействия криминальным явлениям в финансовой сфере. Более того, для этой модели характерна высокая внутренняя криминогенность, порождающая не только криминальное и криминализированное экономическое поведение, но и «размывающая» границы между бизнесом и властью в их возможностях по разграничению сфер влияния [3].

Какие специфические черты получил сегодняшний характер криминализации финансовых отношений в отечественной экономической модели?

Во-первых, на социальную арену вышел третий субъект теневой экономики - наряду с традиционной и экономической преступностью - организованная преступность. Область ее криминальных интересов масштабные хищения бюджетных средств и средств внебюджетных фондов. И это породило борьбу теневого права организованной преступности с официальным правом, результаты которой ставят под угрозу криминализацию общество в целом [4].

Во-вторых, появление нового объекта криминологических исследований - интрузивно-деструктивномимикрийной преступности [2], сформировавшей такую систему финансовых отношений, которая наносит ущерб не только интересам национальным, но уже и международным интересам.

В-третьих, в результате глобализации происходят процессы снижения значимости национальной идентичности. Представители национальной элиты перестают связывать себя со своим государством, они начинают идентифицировать себя и свои интересы с транснациональными, глобалистическими целями [5].

Влияние названных процессов видоизменяет механизмы криминализации общественных отношений, расширяет сферы их распространения и проникновения. Непрекращающаяся криминализация российского 
общества - за счет сращивания власти и криминала - в конечном итоге способна превратить наше государство из криминализованного в криминальное.

Каким нам представляется механизм противодействия криминализации финансовых отношений как угрозе возможностям финансового обеспечения экономического роста в России?

При формировании такого механизма исходить нужно из того, что без учета влияния факторов глобализации и идущей технологической революции невозможно ни обеспечение экономического роста, ни построение эффективной национальной системы противодействия криминализации финансовых отношений. Только в рамках наднациональных соглашений возможно получение ощутимого эффекта и в созидательной работе, и в борьбе со злом.

По этой причине ключевые инструменты противодействия криминализации финансовых отношений должны носить наднациональный характер, являться международными. И одна из базовых целей международного сотрудничества в этой сфере - запретить офшорные юрисдикции.

Для России решение этой задачи представляется первостепенной по целому ряду причин [6]:

- офшоры препятствуют экономическому росту в нашей стране;

- их наличие увеличивают неравенство среди населения;

- они могут рассматриваться - без преувеличения - как инструмент коррупции и противоправной деятельности;

- иностранные банки позволяют секретным компаниям скрывать незаконно нажитые в нашей стране деньги;

- экономических обоснований для существования налоговых гаваней нет, поскольку они не повышают нашего благосостояния и не способствуют развитию экономики;

- согласно зарубежным исследованиям в офшорах находится не менее $\$ 1.0$ трлн российских активов, и эта сумма - скорее всего - не будет уменьшаться в связи с рецессией в нашей экономике.

Примерно на 30-50 \% глобальных потоков прямых иностранных инвестиций приходится на сети оффшорных подставных компаний, созданных юридическими и физическими лицами для налоговых и других целей [16].

Кроме того, офшоры опасны и для состояния мировых экономических процессов. И здесь несколько причин [6]:

- их наличие искажает процессы, реально происходящие в глобальной экономике, так как огромные активы и прибыли оседают в фиктивных компаниях, которые не ведут реальной хозяйственной деятельности;

- офшоры сформировали серый сектор глобальной финансовой системы, в котором сосредоточены незаконно нажитые капиталы. Эти деньги во многом подпитывают коррупцию;

- локальные меры отдельных государств не дают должного эффекта [13]. Более того офшоры используются отдельными государствами в узконациональных интересах [14], [15];

- борьба с офшоризацией на национальном уровне не эффективна. Реальный эффект может быть достигнут только с помощью прозрачных инструментов, действие которых распространено на все страны нашей планеты.

Сторонники борьбы с офшорами считают, что механизм противодействия такой практике должен включать: принятие в статусе международного стандарта акта публичной регистрации конечных собственников компаний; применение международных санкций к юрисдикциям, не соблюдающим этот стандарт. Стратегическая цель - наличие прозрачного реестра собственников всех мировых активов и возможности отслеживания всех транзакций с этими активами. Угрозы наказания - в форме отказа от любых контактов с банками, не раскрывающими имена своих вкладчиков, а также во введении торгового эмбарго на продукцию офшорной территории - должны сделать механизм такого противодействия реалистичным.

Не менее значимым направлением международного сотрудничества - для обеспечения чистоты финансовых рынков - является вхождение России в Группу разработки финансовых мер по борьбе с отмыванием денег (ФАТФ), участие в Евразийской группе по противодействию легализации преступных доходов и финансированию терроризма (ЕАГ).

Российская Федерация активно включилась в работу по противодействию легализации (отмыванию) доходов, полученных преступным путем. Сегодня основным государственным органом, контролирующим подозрительные операции (по законодательно определенным признакам, отражающим возможную направленность на легализацию преступных доходов), является Федеральная служба по финансовому мониторингу. При этом Банк России - в координации с ФСФМ - разрабатывает нормативные акты и рекомендации для коммерческих банков в их работе по мониторингу такой противоправной деятельности.

Организационными решениями такой работы явились:

- создание структурного подразделениями по противодействию легализации (отмыванию) доходов, полученных преступным путем, и финансированию терроризма. Важно, что эта структура (или должностное лицо) является самостоятельным органом банка и не может входить в состав службы внутреннего контроля; 
- принятие программ, регламентирующих правила внутрибанковского контроля по организации этой работы (Программа идентификации кредитной организацией своих клиентов..., Программа выявления в деятельности клиентов операций, подлежащих обязательному контролю..., Программа проверки информации о клиенте..., Программа хранения информации и документов..., Программа, определяющая порядок организации в кредитной организации работы по отказу от заключения договоров банковского счета (вклада)...).

Усилия Банка России по регламентации работы служб внутреннего контроля коммерческих банков, безусловно, затруднили и сделали менее эффективными операции субъектов, занимающихся легализацией доходов, полученных преступным путем.

Наряду с участием в формировании международного механизма противодействия криминализации финансовых отношений, в нашей стране необходимо повышать действенность работы отечественных институтов противодействия посредством повышения эффективности как уже имеющихся в их распоряжении средств, так и создании новых современных инструментов локализации и борьбы с преступлениями в финансово-кредитной сфере.

Принятие законодательных актов и нормативных документов исполнительной власти в этой сфере должно обеспечить появление эффективных правовых средств, способных решить три задачи: блокировать регулятивные правила криминальных традиций и обычаев экономической преступности; обеспечить неотвратимость наказания и применение эффективных санкций за совершенные преступления; создать условия экономической неэффективности криминальной экономической деятельности [4].

И, конечно, правила игры здесь задает Банк России. В своем анализе сложившей ситуации на финансовом рынке [7] он отмечает действие ряда факторов, в том числе невысокий уровень доверия к некредитным финансовым организациям из-за высокого уровня злоупотреблений в отрасли при недостаточной интенсивности надзорной деятельности и отсутствии механизмов воздействия на недобросовестных участников.

В этой связи Банком России намечено принятие мер по дестимулированию недобросовестного поведения на финансовом рынке. Особое внимание уделяется взаимодействию Банка России с правоохранительными органами по ряду направлений:

- недопущение на рынок финансовых организаций без наличия лицензии;

- пресечение незаконной деятельности по выдаче потребительских займов нелегальными кредиторами;

- применение модели автоматизированного поиска нелегальных участников, построенной по технологии Big Data, позволяющей на постоянной основе отслеживать факты незаконной деятельности по выдаче потребительских займов;

- реализация мероприятий, направленных на ограничение недобросовестного поведения и противодействие использованию криминальных бизнес-практик;

- сокращение времени на выявление недобросовестных практик поведения, сбор доказательной базы, а также повышения оперативности передачи материалов правоохранительным органам [7].

Самостоятельно решаемая проблема - расширить практическое использование норм по противодействию неправомерному использованию инсайдерской информации. Регулятор планирует создать условия, при которых выгода от недобросовестного поведения и для организации, и для сотрудника будет ниже, чем потери от применения мер принуждения.

В целом работа Банка России по установлению регулятивных требований, минимизирующих процессы криминализации российского финансового рынка, направлена на поиск оптимального соотношения между издержками отрасли на исполнение этих требований и уровнем свободы осуществления предпринимательской деятельности.

К числу мер противодействия криминализации финансовой сферы может быть отнесено и развитие механизма взаимодействия органов внутренних дел и системы кредитно-финансовых институтов по противодействию теневым явлениям в сфере кредитно-расчетных отношений.

Ведь до настоящего времени существенной проблемой, снижающей эффективность противодействия теневым экономическим явлениям, остается недостаточная проработанность способов информационного обмена системы кредитно-финансовых институтов и органов внутренних дел на региональном уровне. Как результат нарушение порядка формирования статистических баз данных. Это обстоятельство усложняет возможность применения информации как основы реализации управленческих решений по противодействию криминализации финансовой сферы.

В качестве базы для развития названного взаимодействия может выступить Интегрированная система информационно-аналитического обеспечения исполнительных органов государственной власти СанктПетербурга. Возможности данной системы - на основе сбора информации от органов исполнительной власти города, в том числе и от органов внутренних дел, - позволяют на средствах автоматизированного информационного комплекса «Прогноз СПб» с использованием производственного и распределительного методов оценивать и прогнозировать величины теневой экономики [9].

При этом представляется, что включение еще одного инструмента в механизм взаимодействия органов внутренних дел и системы кредитно-финансовых институтов повысит результативность совместных усилий. Речь 
идет об адаптированном методе FMEA-анализа (причин и последствий потенциальных дефектов), когда под «причинами» понимается совокупность детерминант криминализации сферы кредитно-расчетных отношений, под «дефектами» - непосредственно формы проявления теневых явлений в сфере кредитно-расчетных отношений [8]. Использование этого подхода позволяет оценивать риск подверженности сферы кредитнорасчетных отношений воздействию теневых экономических явлений совместными экспертными усилиями представителей финансовых институтов и подразделений по борьбе с экономической преступностью.

Наличие именно таких - особенно количественных - оценок способствует объективности в принятии решений по противодействию криминализации финансовых отношений как угрозе возможностям финансового обеспечения стабильного экономического роста нашей страны.

\section{Литература}

1. Указ Президента Российской Федерации от 31 декабря 2015 года N 683 "О Стратегии национальной безопасности Российской Федерации"//Собрание законодательства Российской Федерации от 4 января 2016 г. N 1 (часть II) ст. 212.

2. Клеймёнов И.М. Криминализация общественных отношений // Вестник Омского университета. Серия «Право». 2013. № 3 (36). С. 200-207.

3. Колесников В.В. Криминогенность современных моделей экономики - источник глобального финансовоэкономического кризиса // Криминология: вчера, сегодня, завтра. - 2010. - № 1 (18). - С. 163-191.

4. Привалов K.B. Взаимодействие теневого и легального права в современной России как угроза безопасности общества / Экономическая безопасность личности, общества, государства: проблемы и пути обеспечения. Материалы ежегодной всероссийской научно-практической конференции. 21.04.2016 г. СПб.: Изд-во СПб ун-та МВД России, 2016.

5. ПУудовочкин Ю.Е. Концепция столкновения цивилизаций как теоретическая основа мировой криминологии // Криминологический журнал Байкальского государственного университета экономики и права. 2010. №4. C.10- 19.

6. Хачатуров А. Глобализация против офшоров. // Новая газета. 2016. № 49.

7. Основные направления развития финансового рынка Российской Федерации на период 2016-2018 годов. Банк России. 26.05.2016. Режим доступа: http://cbr.ru/finmarkets/files/development/onrfr_2016-18.pdf.

8. Ахремцева В.Л. Механизм противодействия теневым экономическим явлениям в сфере кредитно-расчетных отношений [Электронный ресурс] // Управление экономическими системами. - 2013. - №8(56).

9. Громов И.А. Оценка и прогнозирование влияния теневой экономики на состояние экономической безопасности Санкт-Петербурга // Труды СПИИРАН. 2014. Вып. 4 (35).

10. Нудель С.Л. Общая характеристика уголовно-правовой ситуации в сфере охраны финансовых отношений // Ученые труды Российской академии адвокатуры и нотариата. 2014. № 1 (32).

11. Ефремов Р.С. Проблема криминализации нецелевого расходования бюджетных средств в современном уголовном законодательстве // Дифференциация и индивидуализация ответственности в уголовном и уголовно-исполнительном праве. Материалы международной научно-практической конференции, посвященной 75-летию доктора юридических наук, профессора заслуженного деятеля науки Российской Федерации Льва Леонидовича Кругликова. Под редакцией В. Ф. Лапшина. 2015. С. 234-242.

12. Купрещенко Н.П. Противодействие теневой экономике в системе обеспечения экономической безопасности России (теоретико-методологический подход). Диссертация на соискание ученой степени доктора экономических наук / Академия экономической безопасности Министерства внутренних дел Российской Федерации. Москва, 2008.

13. Chamon, M.A, Garcia, M.B Capital controls in Brazil: Effective? // Journal of International Money and Finance. Volume 61, March 01, 2016, P. 163-187.

14. Minikin, R. Lau, K The Offshore Renminbi: The Rise of the Chinese Currency and Its Global Future. - Hong Kong. Wiley Blackwell, Standard Chartered Bank, Hong Kong, 2015.

15. Grasmik, K.I Alternative assessment of volume and industry structure of foreign direct investment in Russia // Studies on Russian Economic Development .Volume 26, Issue 3, 2015, P. 218-224.

16. Haberly, D.A Wójcik, D. Regional blocks and imperial legacies: Mapping the global offshore FDI network // Economic Geography. 2015. № 2.

\section{References}

1. The decree of the President of the Russian Federation of December 31, 2015 N 683 "About the Strategy of national security of the Russian Federation"//the Russian Federation Code. of January 4, 2016 N 1 (part II) of Art. 212.

2. Kleymyonov I. M. Criminalization of the public relations//Bulletin of the Omsk university. Series "Right". 2013. No. 3 (36). P. 200-207. 
3. Kolesnikov V. V. Criminality of modern models of economy - a source of global financial and economic crisis // Criminology: yesterday, today, tomorrow. - 2010. - No. 1 (18). - P. 163-191.

4. K.V's halts. Interaction of the shadow and legal right in modern Russia as threat to security of society / Economic security of the personality, society, state: problems and ways of providing. Materials of an annual All-Russian scientific and practical conference. 4/21/2016 SPb.: SPb publishing house un-that Ministry of Internal Affairs of Russia, 2016.

5. Pudovochkin Yu.E. Concept of collision of civilizations as theoretical fundamentals of world criminology // Criminological magazine of the Baikal state university of economy and right. 2010. No. 4. P. 10-19.

6. Khachaturov A. Globalization against offshores.//New newspaper. 2016. No. 49.

7. The main directions of development of the financial market of the Russian Federation for 2016-2018. Bank of Russia. 5/26/2016. Access mode: http://cbr.ru/finmarkets/files/development/onrfr_2016-18.pdf.

8. Akhremtseva V.L. The mechanism of counteraction to shadow economic events in the sphere of the credit and accounting relations [An electronic resource] // Management of economic systems. - 2013. - No. 8(56).

9. I. A. Otsenk's thunders and forecasting of influence of shadow economy for a condition of economic security of St. Petersburg//Works SPIIRAN. 2014. Issue 4 (35).

10. Nudel S.L. A general characteristic of a criminal and legal situation in the sphere of protection of the financial relations // Scientific works of the Russian academy of legal profession and a notariate. 2014. No. 1 (32).

11. Efremov R.S. A problem of criminalization of an inappropriate expenditure of budgetary funds in the modern criminal legislation // Differentiation and individualization of responsibility in the criminal and criminal and executive law. Materials of the international scientific and practical conference devoted to the 75 anniversary of the doctor of jurisprudence, professors of the honored worker of science of the Russian Federation Lev Leonidovich Kruglikov. Under V. F. Lapshin's edition. 2015. P. 234-242.

12. Kupreshchenko N.P. Counteraction to shadow economy in system of ensuring economic security of Russia (teoretiko-methodological approach). The thesis for a scientific degree competition Doctor of Economics / Academy of economic security of the Ministry of Internal Affairs of the Russian Federation. Moscow, 2008.

13. Chamon, M.A. Garcia, M.B Capital controls in Brazil: Effective?//Journal of International Money and Finance. Volume 61, March 01, 2016, P. 163-187.

14. Minikin, R. Lau, K The Offshore Renminbi: The Rise of the Chinese Currency and Its Global Future. - Hong Kong. Wiley Blackwell, Standard Chartered Bank, Hong Kong, 2.

15. Grasmik, K.I Alternative assessment of volume and industry structure of foreign direct investment in Russia // Studies on Russian Economic Development .Volume 26, Issue 3, 2015, P. 218-224.

16. Haberly, D.A Wójcik, D. Regional blocks and imperial legacies: Mapping the global offshore FDI network // Economic Geography. 2015. № 2. 